\title{
Ralstonia pickettii Biovariant 1
}

National Cancer Institute

\section{Source}

National Cancer Institute. Ralstonia pickettii Biovariant 1. NCI Thesaurus. Code C124368.

A subspecies of R. pickettii positive for tartrate and maleate, fermentation of lactose and maltose, and nitrate reduction. 